\title{
Cytogenetic Study of 48 Patients with Multiple Myeloma and Related Disorders
}

\author{
Takashi Nimura, Ikuo Miura, Yoshimi Kobayashi, Tomoko Yoshioka, \\ Masaaki Kume, Naoto Takahashi, Makoto Hirokawa, \\ Akira B. Miura and Ken-ichi Sawada
}

We studied 48 patients with multiple myeloma and its related disorders (plasma cell dyscrasias: PCD). Clonal changes were observed in 19 patients (39.6\%), which included 9 untreated and 10 treated patients. Chromosomal gains of 3, 11 and loss of 13 were the most frequent numerical chromosome aberrations. Chromosome 13 was lost at an early stage and $17 \mathrm{p}$ (p53) abnormality appeared in an advanced stage of the disease. The most common additional region was $1 \mathrm{q}$ which contained a locus of the IL-6 receptor gene instead of $7 \mathrm{p}$, the locus of the IL- 6 gene. The break points were clustered at $1 \mathrm{p} 13,6 \mathrm{q} 21,7 \mathrm{p} 11.214 \mathrm{q} 32,17 \mathrm{p} 11$ and 19 p13.3, which were the loci of protooncogenes, tumor suppresser genes or immunoglobulin-related genes. Three patients showed a balanced translocation of $\mathrm{t}(11 ; 14)(\mathrm{q} 13 ; \mathrm{q} 32)$. The characteristic features of chromosomal changes in PCD were frequent chromosomal gains and losses and rare balanced translocations. These findings are similar to those found in secondary leukemias and solid tumors, rather than de novo leukemias.

Key words multiple myeloma, chromosomal aberration, monosomy 13, IL-6, IL-6 receptor

\section{INTRODUCTION}

Multiple myeloma and its related disorders are malignant diseases of plasma cells (plasma cell dyscrasias: PCD). Chromosome analysis of leukemias has revealed specific changes in the disease. These findings led to the discovery of the genes responsible for each subtype of leukemia ${ }^{1,2}$. These results enabled us to reach a profound understanding of the disease. On the other hand, specific chromosomal changes have been hard to find in PCD despite long-term efforts ${ }^{2-4}$. This may be, in part, because tumor cells with a low mitotic index are hard to obtain metaphase cells. However, the application of fluorescence in situ hybridization (FISH) to these patients revealed that the immunog-

Received: Apr 17, 2003

Revised: Jun 4, 2003

Accepted : Jun 25, 2003

Third Department of Internal Medicine, Akita University School of Medicine, Akita, Japan

Address correspondence and reprint request to Ikuo Miura.

Third Department of Internal Medicine,

Akita University School of Medicine, 1-1-1 Hondo, Akita,

010-8543, Japan. lobulin heavy chain gene $(I G H)$ is frequently involved in the chromosomal translocations in multiple myeloma ${ }^{5}$. The partner genes of $I G H$ (14q32) include FGFR3/MMSET, MUM1, and $M A F$ in addition to CyclinD1 of $\mathrm{t}(11 ; 14)(\mathrm{q} 13 ; \mathrm{q} 32)$ and $M Y C$ of $\mathrm{t}(8 ; 14)(\mathrm{q} 24 ; \mathrm{q} 32)^{6,7}$. Although the FISH technique has an advantage over cytogenetic studies conducted with metaphase analysis to detect these changes in tumors of low proliferative capacity, only the cytogenetic study detected chromosomal changes as a whole and enabled us to evaluate the clonal evolution and to provide clues in the search for novel genes. It is also known that there are geographical and racial differences in incidence ${ }^{3,8-16}$. To expose the cytogenetic background it may be necessary to compare the outcomes of clinical studies. We describe cytogenetic data obtained from 48 patients with PCD in Akita prefecture, Japan.

\section{MATERIALS AND METHODS}

\section{Patients}

We studied 48 patients with PCD. The patients' clinical features are shown in Table 1. This study 


\section{T. Nimura et al.}

included 32 untreated patients and another 20 patients had prior chemotherapy for PCD. Among the 48 patients, three patients had histories of chemotherapy for lung cancer, renal pelvis and renal cell carcinoma. Twenty-eight patients were male and 20 female. The age range was 28 to 89 years old (median 59). Diagnosis and clinical stage were assigned according to those of SWOG (Southwest Oncology Group ${ }^{17}$ and Durie \& Salmon ${ }^{18}$. The 48 patients included 37 with multiple myeloma (MM), 6 with plasma cell leukemia $(\mathrm{PCL})^{19}, 3$ with macroglobulinemia (WM) and 2 with monoclonal gammopathy of undetermined significance (MGUS) ${ }^{20}$. Two patients with erythroleukemia and myelodysplastic syndrome (MDS) that occurred after treatment for $\mathrm{MM}$ are included. Immunoglobulin subclasses were 18 patients with IgG, 16 with $\operatorname{IgA}, 2$ with IgD, 3 with non-secretory type and 3 with IgM. Kappa type light chains were present in 29 patients and lambda type in 18. Ten patients were in clinical stage I, 5 in stage II and 28 in stage III according to Durie and Salmon ${ }^{18}$.

\section{Methods}

We used a standard technique for chromosome analysis. Bone marrow was aspirated from patients and cultured overnight in RPMI1640 medium supplemented by $20 \%$ fetal bovine serum without a mitogen at $37^{\circ} \mathrm{C}$ in a $5 \% \mathrm{CO}_{2}$ incubator. Colcemid at $0.02 \mu \mathrm{g} / \mathrm{ml}$ was added 2 hours before harvest. Cells were exposed to a hypotonic solution of 0 . $075 \mathrm{M} \mathrm{KCl}$ for $20 \mathrm{~min}$ at room temperature and fixed with methanol and acetic acid (3:1). Fixed cells were spread on slides and dried over steam. The G-band after the treatment by trypsin was used for karyotypic analysis. Karyotypes were described according to ISCN $1995^{21}$.

\section{RESULTS}

All the karyotypes of patients with abnormal clones are shown in Table 1. All patients having chromosome abnormalities were mosaic.

Clonal chromosome abnormalities were found in 19 patients (39.6\%) and 4 patients showed a single cell abnormality (SCA). Fifteen of 37 patients with MM (40.5\%), and 4 of 6 patients with PCL showed clonal chromosome abnormalities, but none of the WM or MGUS patients showed chromosomal changes. Prior to chemotherapy 9 of 32 patients (28.1\%) showed abnormal clones, including 6 of 23 patients with MM and 3 of 5 patients with PCL. Two patients with MM showed only SCA. Patients examined after chemotherapy showed clonal chromosome changes in $9 \mathrm{MM}$ patients and one PCL of 20 patients $(50 \%)$. Among patients who had the second time of chromosome analysis, 3 of 4 patients showed chromosome abnormalities at a later time, including 2 patients who were at a leukemic phase.

\section{Numerical chromosome aberrations}

The modal chromosome number is shown in Fig. 1. The range of modal chromosome number was hypodiploidy and the modal number of the chromosome was 45. Chromosomes gained were $+3,+5,+10,+11$ and lost were $-13,-16,-18$, -21 and $-\mathrm{Y}$ (Fig. 2). Chromosome changes at stage III were $+5,+10,-13,-21$ and $-\mathrm{Y}$. Loss of chromosome 13 was found in untreated patients and $\varkappa$ type. Their survival times were $3.5,4,10$ and 7 months, respectively and the patients associated with -13 were resistant to chemotherapy. The Y chromosome was lost in patients at 38, 45, and 47 years of age.

\section{Structural chromosome aberrations}

Structural changes of $1,6,14,17$ and 19 were found frequently (Fig. 3). Five types of change were found in more than one case, this included 4 deletions and one balanced translocation of $\mathrm{t}(11 ; 14)(\mathrm{q} 13$; q32). Deletion types were distributed as $\operatorname{del}(1)(\mathrm{p} 13)$ in 5 patients, $\operatorname{del}(1)(q 21)$ in $2, \operatorname{del}(2)(q 23)$ in 2 and $\operatorname{del}(6)(q 21)$ in 3 patients.

\section{Chromosomal gains and losses}

Common added and deleted regions are shown in Fig. 4. The gain of $1 \mathrm{q}(1 \mathrm{pl3} \rightarrow 1 \mathrm{qter})$ was at the most common region.

The del(1)(p13) was found in 5 patients, including 3 patients with $\mathrm{MM}$ at stage III, one PCL and one patient who progressed from MM to PCL. The $\operatorname{del}(1)(q 21)$ was found in a patient with PCL and PCL progressed from MM. The $\operatorname{del}(2)(q 23)$ was found in two patients with MM (IgD) and PCL occurred 4 years after treatment of a renal cell carcinoma. The $\operatorname{del}(6)(q 21)$ was found in PCL, MM and MM with MDS. Their survival times were 7, 4, and 2 months, respectively. 


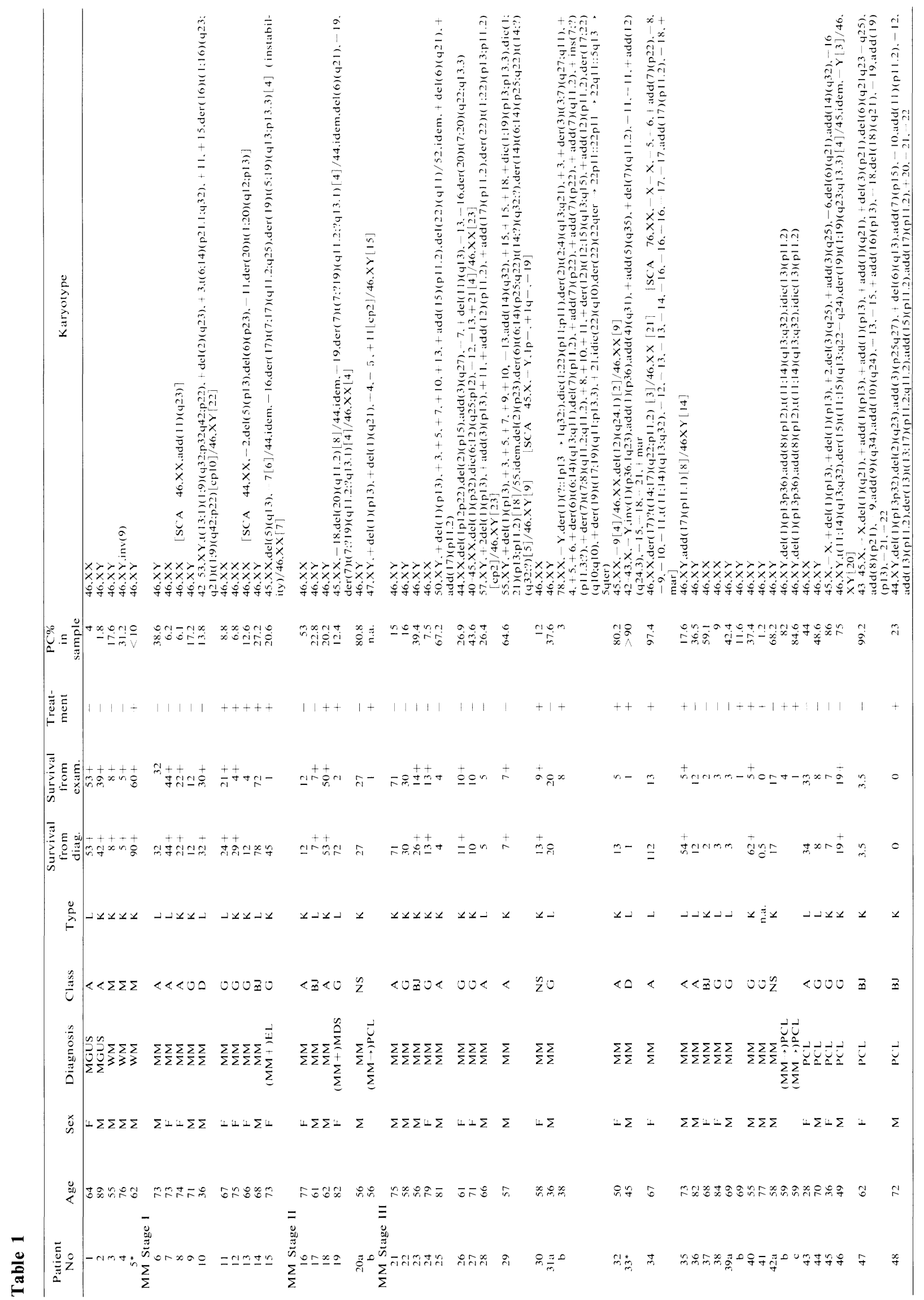




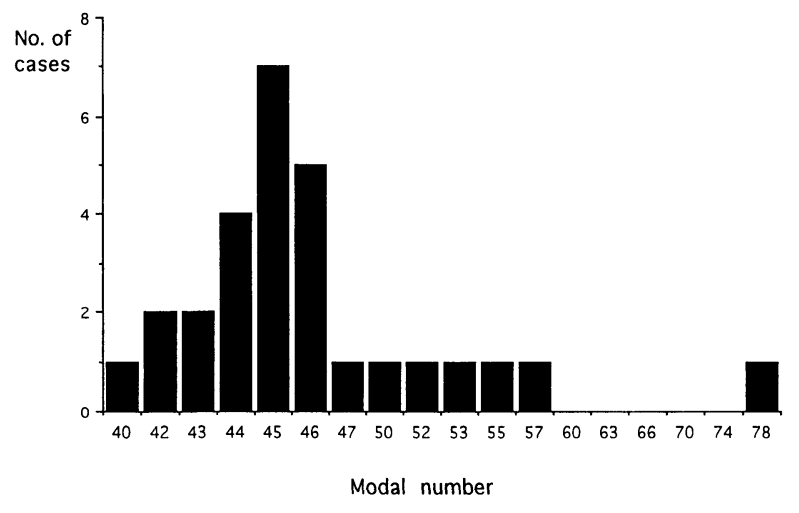

Fig. 1. Modal chromosome number.

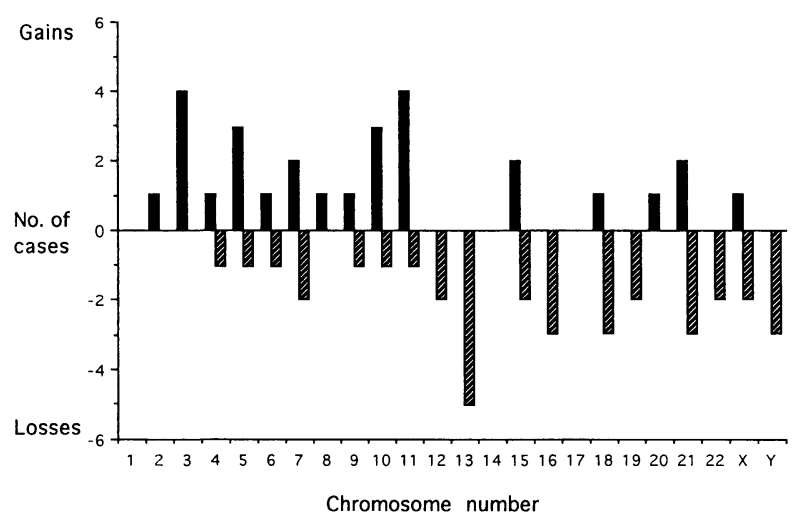

Fig. 2. Clonal gains and losses of whole chromosomes in 48 patients with PCD. Solid bars and crosshatched bars represent chromosome gain and loss, respectively.

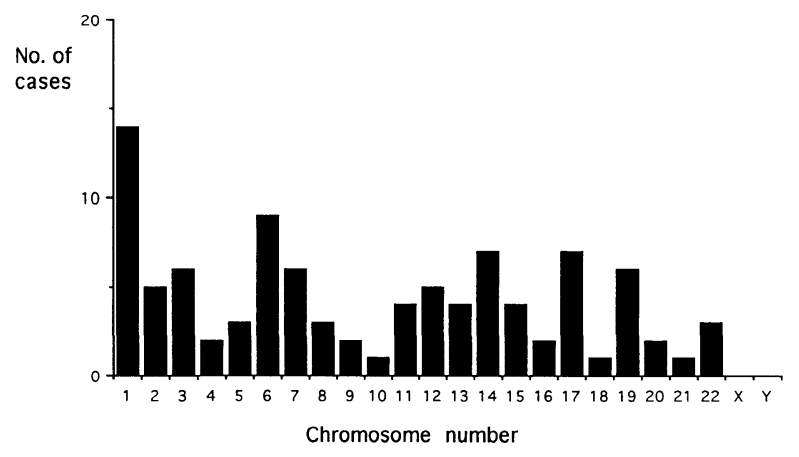

Fig. 3. Structural abnormalities found in each chromosome.

\section{Translocations}

A balanced translocation, $t(11 ; 14)(q 13 ; q 32)$, was observed in two patients with PCL and one patients with SCA. The only balanced translocation

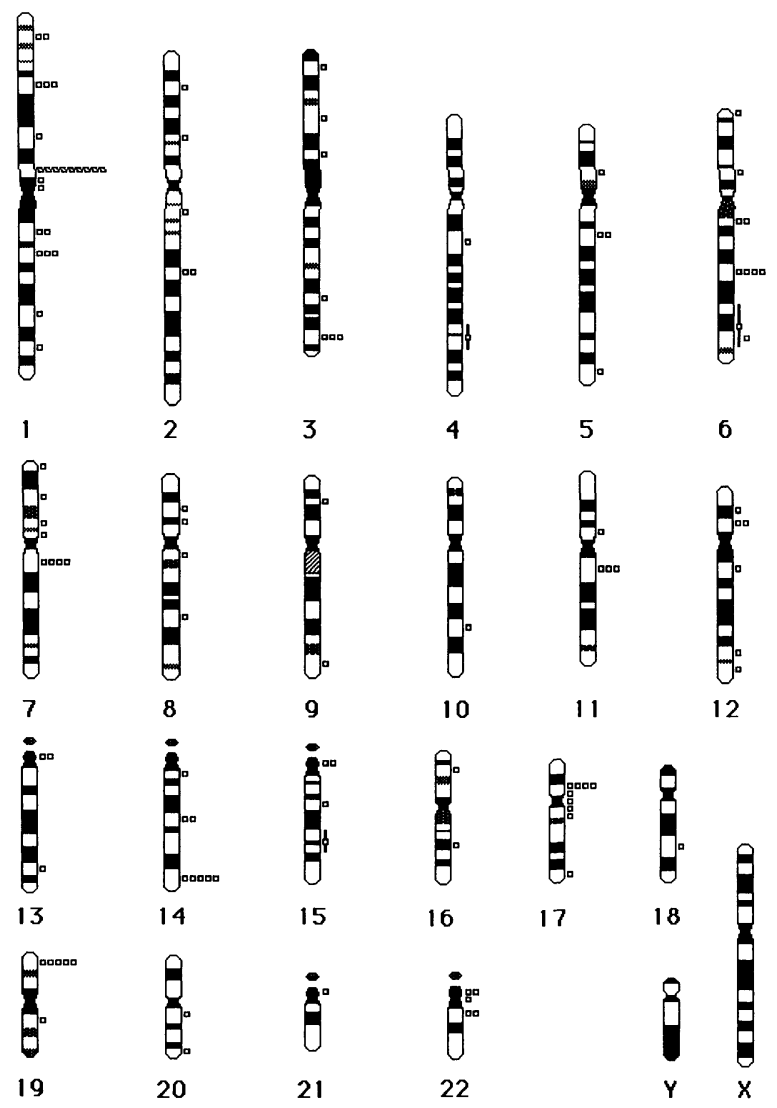

Fig. 4. Ideogram depicting breakpoints for clonal chromosomal rearrangements seen in 48 patients with PCD.

found in more than a patient was $\mathrm{t}(11 ; 14)(\mathrm{q} 13 ; \mathrm{q} 32)$. The others were all unbalanced translocations, which included $\operatorname{add}(12)(\mathrm{p} 11.2)$ in 2 , add(14)(q32) in 2 , and $\operatorname{add}(17)(\mathrm{p} 11.2)$ in 3 patients.

\section{Break points cluster regions}

All breakpoints in clonal abnormality are illustrated in Fig. 4. The sites of clustered regions were 1 p13 (9 cases), 6q21 (4 cases), 7q11.2 (4 cases), 14q32 (5 cases), 17p11 (5 cases) and 19p13.3 (5 cases). The most frequent loci of chromosomal breaks were found in chromosome 1. Breakpoints of $6 \mathrm{q}$ were frequent. Chromosomal breaks at $17 \mathrm{p} 11$ was found in 4 patients with stage III and one patient with PCL. Five patients had breaks at 19p13.3.

\section{DISCUSSION}

Recent advances in molecular biology have clarified the most important genes in leukemias ${ }^{1,2}$. Based on specific chromosomal changes, many genes 
could be cloned from the chromosomal break points and enabled us to make a diagnosis at the molecular level ${ }^{1,2}$

On the other hand, little of the pathogenesis of myeloma has been clarified. The difficulty in obtaining an abnormal metaphase hampered the further study of molecular basis of PCD. The major cause of this difficulty was the slowly-growing character of myeloma cells $\mathrm{s}^{22}$. It has been confirmed that normal metaphase cells in PCD originate from hematopoietic cells other that plasma cells. Reported rates of chromosomal abnormalities are quite variable, between $27 \%^{9}$ and $46 \%{ }^{8}$, but is approximately $40 \%$ in most published series. Our data showed that $39.6 \%$ of patients had chromosomal changes. These data may depend on the stage of the patients included and on whether the patient received treatment prior to chromosome analysis. Although the initial chromosomal changes were expected to be retained in each patient, many additional abnormalities may be included as a result of secondary events which give an increased proliferative activity to tumor cells. It may follow that abnormal clones are observed in advanced stages of myeloma and that the prognoses of these patients are poor ${ }^{23}$.

The chromosome number was in the range of hypodiploidy, which was associated with a poor prognosis ${ }^{24}$. Numerical changes common to previous data were gains of 3, 5, and loss of 13 . Epidemiological studies have shown that up to one third of MM may emerge from a pre-existing monoclonal gammopathy of undetermined significance (MGUS). A very high incidence of monosomy 13 was observed in MM patients with a history of MGUS ${ }^{25}$. In accordance with the data of previous reports, monosomy 13 was associated with a poor prognosis as reported by several groups who used FISH or conventional cytogenetics ${ }^{26-28}$. Tumor suppresser gene RB is located in chromosome $13 \mathrm{q}_{14}{ }^{2}$. The loss of chromosome 13 may suggest the participation of RB or an unknown gene at 13q14. However, chromosome 13 deletion in chronic lymphocytic leukemia (CLL) has been shown not to guarantee a poor prognosis ${ }^{29}$. The divergent clinical implications of chromosome 13 loss in $\mathrm{MM}$ and CLL remain to be explained until the gene is cloned from the region.

Loss of the $\mathrm{Y}$ chromosome is thought to be part of the aging phenomenon ${ }^{1}$. Our patients were younger than the modal age and $-Y$ was also found at an advanced stage. These may suggest that $-Y$ is not merely an aging phenomenon but the sign of progression of the disease.

Rearrangements of $14 q 32$ were found frequently in the abnormal cases. Over $80 \%$ of MM patients were shown by FISH to involve 14q32 translocations. However, we found no balanced transaction except for $\mathrm{t}(11 ; 14)(\mathrm{q} 13 ; \mathrm{q} 32)^{9}$. This translocation is described as the most frequent chromosome abnormality of multiple myeloma, especially $\mathrm{PCL}^{2,30}$. We did find this translocation in two patients with PCL. There have been conflicting data concerning the prognostic significance of $t(11 ; 14)^{31}$. One recent report suggests that patients with this translocation appeared to have better survival and response to treatment, although they tend to have an aggressive clinical course ${ }^{30}$. This translocation is also found as a specific chromosome change in mantle cell lymphoma $(\mathrm{MCL})^{32}$. Although the site of genetic recombination may differ between MCL in VDJ and $\mathrm{PCL}$ in the class switch region, it is quite interesting that these distinct disease subgroups share the same chromosomal translocation.

Chromosomal changes in PCD had many additions and deletions of chromosomes, and balanced translocations were rare. This characteristic feature is similar to secondary MDS and leukemias and solid tumors rather than de novo leukemias and lymphomas ${ }^{1,2}$

Our data showed frequent chromosome breaks at $1 \mathrm{p} 13$, which is a locus of $\mathrm{N}$-ras, whose mutations may be involved in the progression of myeloma ${ }^{33,34}$.

Loss of 17p11.2-pter was observed frequently. The higher frequency of $\mathrm{p} 53$ gene deletions also has been observed by FISH and comparative genomic hybridization $(\mathrm{CGH})$. The p53 tumor suppresser gene is located in $17 \mathrm{p} 13$. The loss of an allele of $17 \mathrm{p}$ resulted in loss of $\mathrm{p} 53$. Our data showed a deletion of $17 p$ in patients at an advanced stage of disease compared to the patients with monosomy $13^{35-37}$.

Five cases showed a 19 p13.3 abnormality ${ }^{5}$. This locus is involved in $\mathrm{t}(1 ; 19)(\mathrm{q} 23 ; \mathrm{p} 13.3)$ of pre B-ALL. This is a locus of E2A which protein bindes to enhancer elements of the $x$ chain gene. It remained to be cleared whether the same gene is affected between ALL and PCD.

IL-6 was originally described as a differentiating factor for B cells. Subsequent studies have clarified that IL-6 is capable of stimulating the growth of myeloma cells ${ }^{38}$. Fresh myeloma cells often produce IL-6 and express the IL-6 receptor (CD126: 1q21, CD130: 5q11). While some experiments suggest that IL- 6 is produced by the bone marrow stromal cell (paracrine mechanism), others 
have found that IL-6 is produced mainly by plasma cells (autocrine loop) in response to exogenous IL$6^{39}$. The sequence of IL-6 in MM remains controversial. Our data support an increase of IL-6 receptors to enhance production of IL-6, which may support the paracrine mechanism (Fig. 5).

Two treatment-related disorders occurred, myelodysplastic syndrome (MDS) and M6 (FAB classification). Each case had 5q-, -7, 7q-, which are changes characteristic of treatment with alkylating agents ${ }^{2}$. It has been reported that secondary leukemia increases in patients treated with a cumulative dose of melphalan greater than $700 \mathrm{mg}$. Our two patients had approximately 4 years' history of treatment with melphalan, at $660 \mathrm{mg}$ in MDS and 1000 $\mathrm{mg}$ in $\mathrm{M6}$, respectively.

Experience over decades clearly shows that finding specific chromosome changes in a disease or its subgroup lead to great advances in the understanding of the disease. For this purpose, chromosome analysis is essential to steady advances in PCD. As this and previous studies show, standard cytogenetic techniques have difficulty obtaining metaphase in

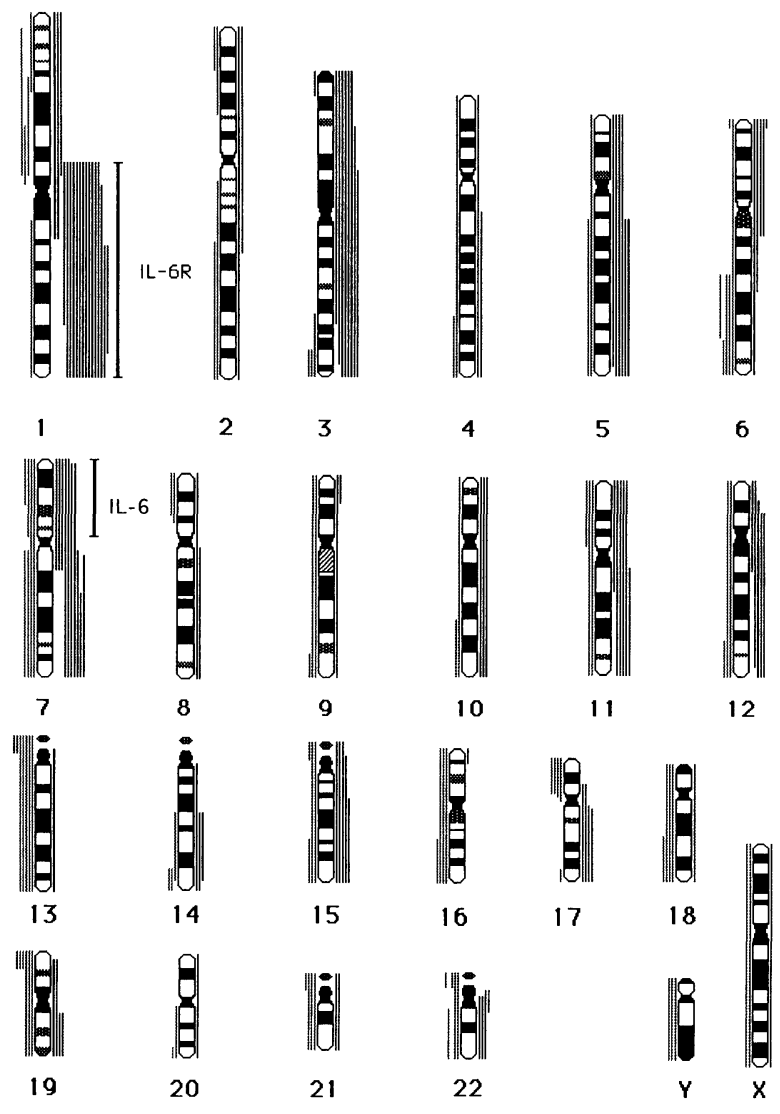

Fig. 5. Schematic representation of regional gains (right) and losses (left). the early stage of PCD and in analyzing complex chromosomal abnormalities, which may hamper finding disease-specific chromosomal changes. Specific stimulating factors of myeloma cells, such as IL6 , may be needed to overcome this limitation ${ }^{22}$. It appears clear that multiple adjunct techniques to G-banding, including FISH, CGH and multicolor spectral karyotyping $(\mathrm{SKY})^{40}$, are necessary to resolve the complex karyotypes of MM. These data may be required in addition to cytogenetic data in leading to further advances.

\section{REFERENCES}

1 Sandberg AA. The chromosomes in human cancer and leukemia 2nd ed. New York, Elsevier, 1990

2 Heim S, Mitelman F. Cancer cytogenetics. New York, Wiley-Liss, 1995

3 Liang W, Hopper JE, Rowley JD: Karyotypic abnormalities and clinical aspects of patients with multiple myeloma and related paraproteinemic disorders. Cancer 44 : 6330-6644, 1978

4 Sawyer JR, Waldron JA, Jagannath S, Barlogie B : Cytogenetic findings in 200 patients with multiple myeloma. Cancer Genet Cytogenet 82 : 41-49, 1995

5 Taniwaki M, Nishida K, Ueda Y, Takashima T : Non-random chromosomal rearrangements and their implications in clinical features and outcome of multiple myeloma and plasma cell leukemia. Leukemia and Lymphoma 21: 25-30, 1996

6 Taniwaki M, Matsuda F, Jauch A, Nishida K, Takashima T, Tagawa S, Sugiyama H, Misawa S, Abe T, Kashima K : Detection of $14 q 32$ translocations in B-cell malignancies by in situ hybridization with yeast artificial chromosome clone containing the human IgH gene locus. Blood 83: 2962-2969, 1994

7 Zhan F, Hardin J, Kordsmeier B, Bumm K, Zheng M, Tian E, Sanderson R, Yang Y, Wilson C, Zangari M, Anaissie E, Morris C, Muwalla F, van Rhee F, Fassas A, Crowley J, Tricot G, Barlogie B, Shaughmessy J Jr: Global gene expression profiling of multiple myeloma, monoclonal gammopathy of undetermined significans, and normal bone marrow plasma cells. Blood 99: 1745-1757, 2002

8 Gould J, Alexanian R, Goodacre A, Pathak S, Hecht B, Balogie B: Plasma cell karyotype in multiple myeloma. Blood 71: 453-456, 1988

9 Dewald GW, Kyle RA, Hicks GA, Greipp PR : The clinical significance of cytogenetic studies in 100 patients with multiple myeloma, plasma cell leukemia, or amyloidosis. Blood 66 : 380-390, 1985

10 Jonveaux $\mathrm{P}$, Berger $\mathrm{R}$ : Chromosome studies in plasma cell leukemia and multiple myeloma in 
transformation. Genes Chromosom \& Cancer 4: 321-325, 1992

11 Ueshima Y, Fukuhara S, Nagai K, Takatsuki K, Uchino $\mathrm{H}$ : Cytogenetic studies and clinical aspects of patients with plasma cell leukemia and leukemia macroglobulinemia. Cancer Res 43: 905-912, 1983

12 Lewis JP, Mackenzie MR: Non-random chromosomal aberrations associated with multiple myeloma. Hematol Oncol 2: 307-317, 1984

13 Durie BGM: Cellular and molecular genetic features of myeloma and related disorders. Hematol/ Oncol 6: 463-477, 1992

14 Ferti A, Panani A, Arapakis G, Raptis S : Cytogenetic study in multiple myeloma. Cancer Genet Cytogenet 12: 247-253, 1984

15 Chen K-C, Bevan PC, Matthews JG: Analysis of G banded karyotypes in myeloma cells. J Clin Pathol 39: 260-266, 1986

16 Philip P, Drivsholm A, Hansen NE, Jensen MK, Killmann S-A: Chromosomes and survival in multiple myeloma. A banding study of 25 cases. Cancer Genet Cytogenet 2: 243-257, 1980

17 Durie BGM, Salmon SE: Multiple myeloma, macroglobulinemia and monoclonal gammopathies. In Hoffbrand AV, Brain MC, Hirschi J (eds) : Recent Advances in Hematology. Vol. 2, Churchill Livingstone, 243-261, 1977

18 Durie BGM, Salmon SE : A clinical staging system for multiple myeloma. Correlation of measured myeloma cell mass with presenting clinical features, response to treatment, and survival. Cancer 36 : 842-854, 1975

19 Kyle RA, Maldonado JE, Bayrd ED : Plasma cell leukemia: report on 17 cases. Arch Intern Med 133: 813-818, 1974

20 Kyle RA: Monoclonal gammopathy of undetermined significance (MGUS). Baillière's Clinical Haematology 8: 761-781, 1995

21 ISCN1995: An international system for human cytogenetic nomenclature (1995). In Mitelman F (ed) : Cytogenet Cell Genet, Karger, 1995

22 Lai JL, Zandecki M, Mary JY, Bernardi F, Izydorczyk V, Flactif M, Morel P, Jouet JP, Bauters F, Facon $\mathrm{T}$ : Improved cytogenetics in multiple myeloma: A study of 151 patients including 117 patients at diagnosis. Blood 85: 2490-2497, 1995

23 Calasanz MJ, Cigudosa JC, Odero MD, Ferreira C, Ardanaz MT, Fraile A, Carrasco JL, Solé F, Cuesta B, Gullon A : Cytogenetic analysis of 280 patients with multiple myeloma and related Disorders: Primary breakpoints and clinical correlations. Genes Chromosom Cancer 18 : 84-93, 1997

24 Smadja NV, Bastard C, Brigaudeau C, Leroux D, Fruchart C. Hypodiploidy is a major prognostic factor in multiple myeloma. Blood 98: 2229-2238,
2001

25 Avert-Loiseau H, Li J-Y, Morineau N, Facon T, Brigaudeau C, Harousseau J-L, Grosbois B, Bataille $\mathrm{R}$ : Monosomy 13 is associated with the transition of monoclonal gammopathy of undetermined significance to multiple myeloma. Blood 94 : 2583-2589, 1999

26 Shaughnessy J Jr, Tian E, Sawyer J, Bumm K, Landes R, Bardos A, Morris C, Tricot G, Epstein J, Barlogie B: High incidence of chromosome 13 deletion in multiple myeloma detected by multiprobe interphase FISH. Blood 96: 1511, 2000

27 Barlogie B, Jagannath S, Desikan KR, Mattox S, Vesole D, Siegel D, Tricot G, Munshi N, Fassas A, Singhal S, Mehta J, Anaissie E, Dhodapkar D, Naucke S, Cromer J, Sawer J, Epstein J, Spoon D, Ayers A, Cheson B, Crowley J : Total therapy with tandem transplants for newly diagnosed multiple myeloma. Blood 93 : 55-65, 1999

28 Zojer N, Köningsberg R, Ackermann J, Fritz E, Dallinger S, Krömer E, Kaufmann H, Riedl L, Gissinger $H$, Schreiber S, Heinz R, Ludwig H, Hubner $\mathrm{H}$, Drach $\mathbf{J}$ : Deletion of $13 \mathrm{q} 14$ remains an independent adverse prognostic variable in multiple myeloma despite its frequent detection by interphase fluorescence in situ hybridization. Blood 95 : 1925 1930, 2000

29 Juliusson G, Oscier DG, Fitchett M, Ross FM, Stockdill G, Mackie M, Parker A, Castoldi GL, Guneo A, Kunuutila S, Elonen E, Garton G : Prognostic subgroups in B-cell chronic lymphocytic leukemia defined by specific chromosomal abnormalities. N Engl J Med 323 : 720-724, 1990

30 Fonseca R, Blood EA, Oken MM, Kyle RA, Dewald GW, Bailey RJ, Van Wier SA, Henderson KJ, Hoyer JD, Harrington D, Kay NE, Ness BV, Greipp PR: Myeloma and the $\mathrm{t}(11 ; 14)(\mathrm{q} 13 ; \mathrm{q} 32)$; evidence for a biologically defined unique subset of patients. Blood 99 : 3735-3741, 2002

31 Fonceca R, Witzig TE, Gertz MA, Kyle RA, Hoyer JD, Jalal SM, Greipp PR. Multiple myeloma and the translocation $\mathrm{t}(11 ; 14)(\mathrm{q} 13 ; \mathrm{q} 32)$ : a report on 13 cases. Brit J Haematol. 1998; 101: 296-301

32 Weisenburger DD, Armitage JO: Mantle cell lymphoma-An entity comes of age. Blood 87 : 4483-4494, 1996

33 Ernst TJ, Gazdar A, Ritz J, Shipp MA : Identification of a second transforming gene, rasn, in a human multiple myeloma line with a rearranged c-myc allele. Blood 72: 1163-1167, 1988

34 Kalakonda N, Rothwell DG, Scarffe JH, Norton JD: Detection of N-Ras codon 61 mutations in subpopulations of tumor cells in multiple myeloma at presentation. Blood 98 : 1555-1560, 2001

35 Neri A, Baldini L, Trecca D, Cro L, Polli E, 


\section{T. Nimura et al.}

Maiolo AT: p53 gene mutations in multiple myeloma are associated with advanced forms of malignancy. Blood 81 : 128-135, 1993

36 Mazars G-R, Portier M, Zhang X-G, Jourdan M, Bataille R, Theillet C, Klein B: Mutation of the p53 gene in human myeloma cell lines. Oncogene 7 : 1015-1018, 1992

37 Drach J, Ackermann J, Fritz E, Krömer E, Schuster R, Gisslinger H, DeSantis M, Zojer N, Fiegl M, Roka S, Schuster J, Heinz R, Ludwig H, Huber H : Presence of a p53 gene deletion in patients with multiple myeloma predicts for short survival after conventional-dose chemotherapy. Blood 92: 802809,1998
38 Klein B, Zhang X-G, Lu Z-Y, Bataille R: Interleukin-6 in human multiple myeloma. Blood $85: 863-872,1995$

39 Frassantio MA, Cusmai A, Iodice G, Dammacco F : Autocrine interleukin-6 production and highly malignant multiple myeloma: relation with resistance to drug-induced apoptosis. Blood 97: 483489, 2001

40 Sawyer JR, Lukacs JL, Munshi N, Desikan KR, Singhal S, Mehta J, Siegel D, Shaughnessy J, Barlogie B: Identification of new nonrandom translocations in multiple myeloma with multicolor spectral karyotyping. Blood 92 : 4269-4278, 1998 